ORIGINAL ARTICLE

\title{
Familial Occurrence of Complex Regional Pain Syndrome
}

\author{
Peyman Shirani, Ali Jawaid, Paolo Moretti, Elham Lahijani, Alicia R. Salamone, \\ Paul E. Schulz, Everton A. Edmondson
}

\begin{abstract}
Background: The etiology of complex regional pain syndrome (CRPS) is unknown. Different environmental and genetic factors have been postulated to contribute to CRPS. Methods: We reviewed the clinical data from a cohort of 69 patients with CRPS. Four families were identified with two or more members affected with CRPS yielding a total of nine patients. Six more patients reported the presence of pain symptoms in their family members, however; this could not be clinically confirmed. Results: The case histories of the nine individuals with 'familial' CRPS suggested a younger age at onset and more frequent history of migraine versus the non-familial patients. A pattern of inheritance could not be ascertained. Conclusion: This data supports the hypothesis that CRPS can be familial and hence may have a genetic basis in some families. Larger studies will be needed to ascertain clearer patterns of inheritance and to determine whether the clinical features of 'familial' CRPS are the same as the sporadic form.
\end{abstract}

RÉSUMÉ: Cas familiaux du syndrome douloureux régional complexe. Contexte : L'étiologie du syndrome douloureux régional complexe (SDRC) est inconnue. Certains facteurs environnementaux et génétiques pourraient être en cause. Méthodes : Nous avons révisé les données cliniques d'une cohorte de 69 patients atteints du SDRC. Nous avons identifié quatre familles dont deux membres ou plus étaient atteints de SDRC, soit 9 patients en tout. Six autres patients ont rapporté la présence de douleurs chez des membres de leur famille, sans toutefois que nous puissions le confirmer en clinique. Résultats : L'anamnèse faite chez les 9 individus atteints du SDRC « familial » a mis en évidence un début de la maladie plus précoce et une histoire de migraine plus fréquente chez ces individus que chez les patients dont les apparentés ne sont pas atteints. Aucun mode d'hérédité n'a pu être identifié. Conclusion : Ces données sont en faveur de l'hypothèse selon laquelle le SDRC peut être familial et donc qu'il pourrait exister un fondement génétique dans certaines familles. Des études comportant un plus grand nombre de sujets devront être entreprises pour en établir le mode d'hérédité et déterminer si les manifestations cliniques du $\mathrm{SDRC}$ « familial » sont les mêmes que celles de la forme sporadique.

Can. J. Neurol. Sci. 2010; 37: 389-394

Complex regional pain syndrome (CRPS) is characterized by pain in association with sensory and vasomotor changes in the affected area. The reported incidence of CRPS ranges from 5.5 to 26.2 per 100.000 person years..$^{1-2}$ The disorder commonly affects women (60-81\% of cases) between the ages of 35-45 years. $^{3-4}$

There are two clinical sub-types of CRPS: CRPS I, formerly called reflex sympathetic dystrophy, does not have evidence of nerve lesions, whereas CRPS II, formerly called causalgia, has obvious nerve damage. ${ }^{5}$ The International Association for the Study of Pain (IASP) ${ }^{5}$ diagnostic criteria for CRPS I are 1) the presence of an initiating noxious event or a cause of immobilization; 2) continuing pain, allodynia or hyperalgesia; 3 ) evidence at some time of edema, vasomotor changes or abnormal sudomotor activity in the area of pain; and, 4) the absence of another cause for the pain or dysfunction. The IASP ${ }^{5}$ criteria for CRPS II are: 1) continuing pain, allodynia or hyperalgesia after a nerve injury, not necessarily limited to the distribution of the injured nerve; 2) evidence at some time of edema, vasomotor changes or abnormal sudomotor activity in the area of pain; and, 3 ) absence of another cause for the pain or dysfunction.

From the Department of Neurology (PS, AJ, PM, ARS, PES,), Baylor College of Medicine; Department of Neurology (PES, EAE), The Methodist Hospital; Interventional Neurology, Inc. (EAE, EL), Houston, Texas, USA.

Received October 7, 2009. Final Revisions Submitted December 21, 2009. Correspondence to: Everton A Edmondson, The Methodist Hospital, 6560 Fannin St., Suite 2202, Houston, Texas, 77030, USA. 
The etiology of CRPS remains unclear, but most cases occur after noxious injury (83-98\%). ${ }^{1-2}$ The incidence of chronic headaches in CRPS patients is almost twice that of healthy controls (52.2\% versus $26.1 \%) .{ }^{6}$ However, it is not clear whether a history of chronic headaches is a risk factor for CRPS or is coincidental. A history of smoking has also been proposed as a risk factor for CRPS, but the evidence is inconclusive. ${ }^{7}$

It has also been suggested that genetic factors may contribute to CRPS. Human leukocyte antigen (HLA) typing has been associated with CRPS.$^{8-10} \mathrm{~A}$ two fold increase in the incidence of HLA-A3 and HLA-B7 has been noted in patients with CRPS compared to disease-free controls. ${ }^{8}$ An increased incidence of HLA-DQ1 has also been described in CRPS. ${ }^{9}$ In another study, HLA-DR13 had a much higher frequency than HLA-DQ1. ${ }^{10}$

A positive family history has also been suggested as a risk factor for CRPS ${ }^{11-17}$, but familial occurrence has not been extensively studied. In a Dutch study, 31 CRPS families with two or more affected family members were identified from a nationwide CRPS database. ${ }^{17}$ It was observed that 'familial' patients had a younger age of onset and greater severity of symptoms than 'sporadic' patients. To the best of our knowledge, this is the only larger study of the familial occurrence of CRPS. Clearly, more studies are needed to ascertain the pattern of inheritance and phenotypic expression in patients with familial CRPS. We examined our cohort of 69 patients to ascertain the familial occurrence of CRPS.

\section{Case Series}

We reviewed the clinical charts of 69 patients with CRPS seen at the Interventional Neurology Clinic of The Methodist Hospital, Houston between 2000 and 2007. The data review led to the identification of four families with two or more members affected with CRPS. These patients were contacted via telephone to gather more information about their immediate family members. We also inquired about the presence of CRPS symptoms or other chronic pain conditions in the family. This information was used to draw pedigree charts for the four families (Figure). The number of affected members per family, phenotypic expression and inheritance were assessed for all four families. In addition to these confirmed 'familial' cases, six additional patients in the cohort had indicated a family history of CPRS-like symptoms. However, none of the family members were personally examined by the authors and so they were not included here. A brief description of the confirmed familial cases follows.

\section{Family I}

Three siblings; African-American; Non-consanguineous

Case I: A 32-year-old female developed swelling, hyperpathia and allodynia on her left hand two weeks after carpal tunnel surgery (Figure; Table 1). The symptoms were present beyond the distribution of the median nerve and hence the possibility of CRPS was considered. She was referred to a pain management physician who performed stellate ganglion blockade with transient relief of the pain. Three further stellate blocks were performed with short-term relief. She was then referred to our clinic for confirmation of diagnosis and treatment. On local examination, the patient was found to have shiny skin, coldness in the affected area, and allodynia in the whole left hand. The rest of her examination was unremarkable except for emotional irritability. Her past medical history was positive for migraine. The patient was prescribed topical ketamine $(5 \%)$ admixed with lidocaine (20\%) in a pluronic lecithin organogel based topical compound. She reported marked relief with this treatment over a follow-up interval of three years.

Case II: The brother of the first case is a 33-year-old gentleman who presented to our clinic with "excruciating" pain, tenderness and edema in both hands. The condition developed a

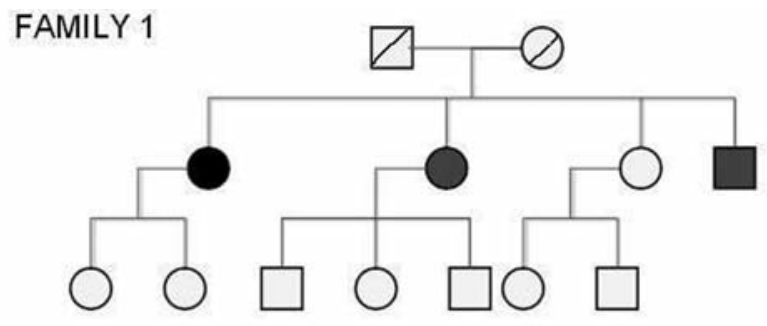

FAMILY 2

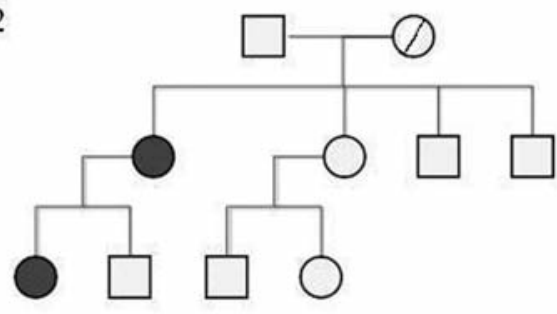

FAMILY 3
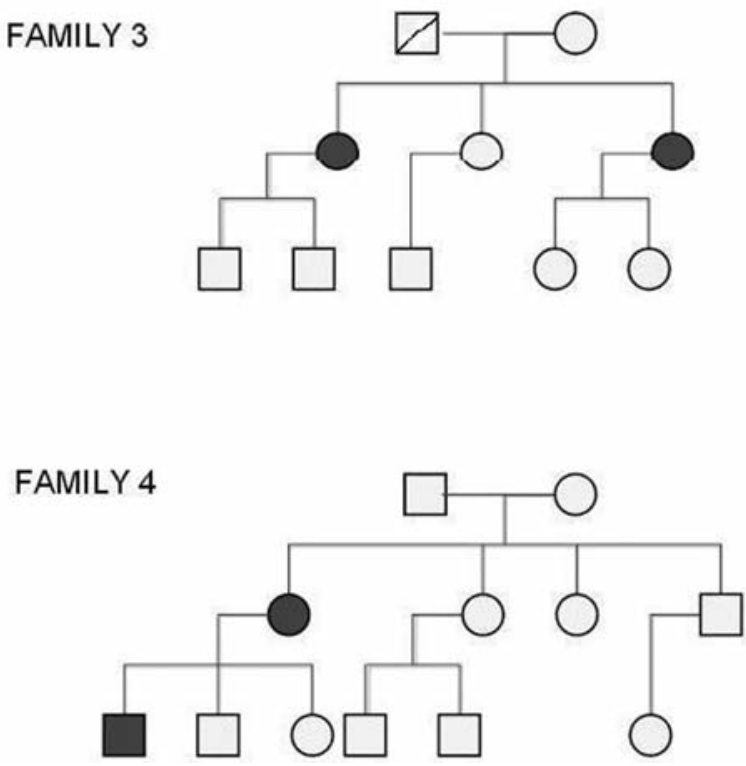

Figure: Pedigrees of CRPS families. Circles indicate females; squares indicate males; crossed-out symbols are deceased individuals; black symbols indicate individuals with CRPS. 
Table 1: Overview of familial CRPS cases

\begin{tabular}{lcccc}
\hline & Age of onset & Sex & Site & $\begin{array}{c}\text { Causative } \\
\text { Factor }\end{array}$ \\
Case I & & Family I & \\
Case II & 32 & F & LUE & Surgery \\
Case III & 33 & M & BUE & Surgery \\
& 35 & F & LUE & Trauma \\
Case I & 20 & Family II & & Unknown \\
Case II & 45 & F & BUE & Unknown \\
Case I & 40 & F & BUE & Surgery \\
Case II & 43 & Family III & & Surgery \\
& & F & LUE & \\
Case I & 10 & F & LUE & Trauma \\
Case II & 46 & M & RLE & Surgery \\
\hline
\end{tabular}

RLE: Right Lower Extremity, LLE: Left Lower Extremity, BUE: Both Upper Extremities, LUE: Left Upper Extremity.

few weeks after bilateral carpal tunnel release surgery. An electromyography/nerve conduction velocity performed after the surgery had demonstrated a normalization of the nerve conduction velocities. On examination, the patient had allodynia and hyperpathia in the median nerve distribution of both hands. Pain improved with dorsiflexion of both hands. Tinel's sign was positive bilaterally. As the patient's physique was very muscular, the possibility of persistent carpal tunnel compression was raised. However, two hand surgeons suggested that this was not the case. A repeat electromyography/nerve conduction velocity study also showed normal bilateral median nerve conductions. A diagnosis of CRPS was then considered. The patient refused stellate blockade and opted for pain medications. He was prescribed a tramadol, ketoprofen and lidocaine compounded cream and a medrol dosepak. The patient returned to work after two years of treatment; however the symptoms continued to persist with a lesser severity.

Case III: This older sister of those two cases is a 35-year-old woman with symptoms of chronic pain and swelling in her left hand, which had started after she twisted it at work. Her past medical history was only significant for migraines. An X-ray of her left wrist was negative for musculoskeletal injuries. On local examination, the patient had massive swelling of her left hand, altered temperature and marked hyperpathia and allodynia. The patient received stellate ganglion blockade with complete relief of her pain, but the relief lasted only 24 hours. The patient received three more nerve blocks and was further tried on lidocaine infusion, mexiletine, steroids, clonidine, fluidotherapy and a variety of other measures, which proved to be ineffective. She was then referred to have unilateral transthoracic sympathectomy. This resulted in elimination of the swelling in the left hand and reduced the pain; however, hyperpathia was transferred to the proximal forearm, arm and left chest wall. The patient continued to have these symptoms over a three year follow-up.

Other family members: None of the other family members had symptoms suggestive of CRPS. However, multiple family members suffered from migraine.

\section{Family II}

Mother and daughter; Caucasian; Non-consanguineous

Case I: This 20-year-old female presented with severe pain, redness and excessive sweating in both hands (Figure; Table 1). Her past medical history was significant for migraine, asthma, endometriosis and depression with a suicide attempt at the age of 15. The patient's physical examination revealed rubor, allodynia, hyperpathia, hyperhydrosis and superficial fissuring of the fingertips. Nerve conduction studies were normal. The patient met most of the criteria of CRPS in both hands but did not have any predisposing/initiating factors. She was treated with steroids, opiates and instructed mobilization. The patient refused further follow-up.

Case II: The 45-year-old mother of Case I presented with symptoms similar to her daughter. Her past medical history was positive for idiopathic small fiber neuropathy. With the exception of absent sural nerve conductions, all remaining nerve conductions were normal. On examination, she was found to have rubor over both palms and fingers, with fissuring of the fingertips, hyperpathia, allodynia and excessive sweating. The patient was treated with stellate block, which resulted in brief relief. She was then prescribed opiates and gabapentin, which provided a sustained reduction of pain. She has since had an uneventful follow-up over three years.

Other family members: No other family members had symptoms of CRPS. There was a positive family history of depression.

\section{Family III}

Two sisters; Caucasian; Non-consanguineous

Case I: This 40-year-old female initially presented to our clinic for treatment of chronic migraine and fibromyalgia, for which she was treated with triptophan and diazepam (Figure; Table 1). The patient later developed Raynaud's phenomenon and tingling in the fifth digit of the left hand. An extensive workup revealed thoracic outlet syndrome, which was treated with resection of the first rib. The patient then developed symptoms of CRPS, including hyperpathia, allodynia, edema and a color change in her left hand. Her hand also became cold and clammy. The patient received a series of three stellate blocks with complete recovery. A one year follow-up was uneventful.

Case II: This 43-year-old sister of Case I had a past medical history of renal transplantation secondary to membranoproliferative glomerulonephritis and scoliosis associated with chronic back pain. She was referred to our clinic for treatment of back pain, which was relieved completely with fentanyl patch and hydrocodone. She then underwent a surgery in which an infected arterio-venous fistula was repaired in her left forearm. Subsequently, the patient presented with swelling, altered color and temperature, allodynia and hyperpathia in the left upper extremity. She received a single stellate block with permanent relief. Mild to moderate back pain persisted for which she continued to use analgesics over a one year follow-up. 
Other family members: The family history was positive for migraine in multiple family members. None of the other family members had symptoms of CRPS.

\section{Family IV}

Mother and son; Caucasian; Non-consanguineous

Case I: A 10-year-old male presented to our clinic with symptoms of burning pain in the right leg, which began after a fall from a fence (Figure; Table 1). The pain was severe enough that it limited his activities significantly. He was placed on home schooling due to his inability to walk to classes. On examination, he had hyperpathia, allodynia and edema in his right leg with a purplish coloration of the skin. Pain extended from the inguinal crease to the mid-pubic area and down the right thigh. The patient's past medical history was unremarkable and his pulses were normal. He was treated with a two week course of prednisone and topical ketamine (5\%) with lidocaine (10\%) in a pluronic lecithin organogel-based compounded cream. The patient was encouraged to mobilize and his mother was warned that inactivity could augment CRPS. After six months, his pain resolved. The patient had lingering signs of emotional irritability and anxiety, for which he was referred to a psychologist.

Case II: The 46-year-old mother of Case I was under the care of another pain management clinician for the treatment of CRPS. Review of her records revealed that she developed persistent swelling, hyperpathia and allodynia in her left lower limb after a partial left knee replacement. The patient received several lumbar sympathetic blocks for pain. She also took gabapentin and hydrocodone/APAP. She had a history of rheumatoid arthritis, systemic lupus erythematosus, migraine and fibromyalgia. This patient came to our clinic for a second opinion. She met all the criteria for CRPS. She was advised to return to her pain management clinician for follow-up and treatment.

Other family members: None of the other family members reported symptoms suggestive of CRPS. The family history was remarkable for rheumatologic disorders and migraine.

\section{Discussion}

A review of the clinical data on 69 CRPS patients seen between 2000 and 2007 led to the identification of four families with two or more members affected with CRPS. Six other patients indicated a positive family history, but we were unable to examine them and did not include them in this report. This suggests a familial occurrence of at least $6 \%$ (four probands in a clinical population of 64 families). However, considering the six unconfirmed familial cases, the familial history could be as high as $15 \%$.

From the pedigree charts for our four families, it is difficult to determine an inheritance pattern or whether a single or multiple inheritance patterns exist. Determining the actual inheritance pattern(s) of familial CRPS will require recruitment of extensive pedigrees, multiple familial cases and a detailed segregation analysis. Nonetheless, the possible modes of inheritance in our familial cases are discussed briefly.

An autosomal dominant inheritance pattern is possible, especially in Families 2 and 4. In Families 1 and 3, autosomal dominant inheritance is also a possibility. In these cases, incomplete penetrance, parental gonadal mosaicism, epigenetic parent of origin effects, anticipation, de-novo mutation or simple non-paternity could account for the apparent absence of disease in multiple generations. An earlier onset is observed in the second generations in Families 2 and 4. This observation is most

Table 2: Studies suggesting a familial occurrence for CRPS

\begin{tabular}{|c|c|c|c|}
\hline Authors & Study type & Year & Key Findings \\
\hline Albert \& Ott & Case report & 1983 & $\begin{array}{l}\text { Algodystrophy described in three brothers with identical HLA-type. First } \\
\text { familial presentation of the disease. }\end{array}$ \\
\hline Erdmann \& Wynn-Jones & Case report & 1992 & $\begin{array}{l}\text { RSD described in two siblings. Both the individuals eventually had to } \\
\text { undergo limb amputation for pain relief. }\end{array}$ \\
\hline Mailis \& Wade & Pilot study & 1993 & $\begin{array}{l}\text { Caucasian women with RSD carrying HLA-DR2 were found to be refractory } \\
\text { to treatment. The study suggested a genetic predisposition to severe form of } \\
\text { the disease. }\end{array}$ \\
\hline Veldman et al. & Cohort & 1993 & $\begin{array}{l}\text { Study of a large cohort, in which five patients reported that one or more of } \\
\text { their blood relatives suffered from symptoms of RSD. }\end{array}$ \\
\hline Bruscas et al. & Case report & 2004 & Recurrent RSD described in two Spanish siblings. \\
\hline Huhne et al. & Cohort & 2004 & $\begin{array}{l}\text { Study on co-segregation of ACE gene genotype with CRPS phenotype. } \\
\text { Study was performed on } 12 \text { CRPS patients belonging to } 6 \text { families. }\end{array}$ \\
\hline de Rooij et al. & Cohort & 2009 & $\begin{array}{l}94 \text { individuals belonging to } 31 \text { CRPS families were described. Familial } \\
\text { patients had a younger age at symptom onset and had involvement of } \\
\text { multiple extremities. A specific pattern of inheritance was not observed. }\end{array}$ \\
\hline Higashimoto et al. & $\begin{array}{l}\text { Retrospective } \\
\text { Review }\end{array}$ & 2008 & $\begin{array}{l}\text { Eight individuals belonging to seven families identified. Pedigree analysis } \\
\text { suggested mitochondrial inheritance. }\end{array}$ \\
\hline
\end{tabular}

$\mathrm{RSD}=$ Reflex sympathetic dystrophy; $\mathrm{ACE}=$ Angiotensin converting enzyme 
likely due to a recruitment bias, rather than the result of true 'anticipation' similar to triple repeat expansion disorders e.g., Huntington's disease. ${ }^{18}$

Another possible inheritance pattern is X-linked dominant inheritance. This is supported by the absence of male-male transmission.

Higashimoto et al earlier (2008) described mitochondrial inheritance in six CRPS families. The studied probands met the Nijmegen criteria of mitochondrial disease and had other manifestations of dysautonomia as well. ${ }^{17}$ Although the pattern of female transmission observed in our families seems consistent with this mode of inheritance, we do not have direct evidence suggestive of mitochondrial inheritance or disease in our small population.

An autosomal recessive inheritance also needs to be considered in pedigrees 1 and 3. However, parents of affected individuals did not share the same ethnic background and the families denied parental consanguinity.

A final possibility is that the clinical characteristics of CRPS are attributable to interactions between two or more genes (oligogenic or complex inheritance). In this scenario, the patterns of Mendelian inheritance will not be followed and there will be a high intra-familial and inter-familial variability in the phenotype characteristics of the patients. A recent study by Rooij et al (2009) estimates a significantly increased occurrence risk in the siblings of CRPS patients under the age of 50. ${ }^{19}$ The findings are somewhat similar to those of a study on cleft palate, an established multifactorial inheritance disorder. A study performed of 6,776 individuals with cleft palate and their 54,000 family members revealed an association between the severity of the anatomical defect and the recurrence risk in the relatives. The recurrence risk was higher in the siblings of a proband with bilateral defect as compared to unilateral defect. ${ }^{20}$ Observation of distinct familial cases in complex diseases is common. It could be explained by chance where the family members already have most of the genetic variants required for the disease presentation and the affected status is determined by a final mutation at a single locus (hence the Mendelian pattern). Alternatively, it could be due to genetic heterogeneity where Mendelian variants of complex diseases exist e.g. maturity onset diabetes of the young.

We examined other studies that also reported on the familial occurrence of CRPS ${ }^{11-17}$, but they also have been unable to ascertain a distinct inheritance pattern. The affected families in each study are small with just a few affected members. Thus, even combining data across studies does not yet yield a conclusive inheritance pattern.

We reviewed the other studies examining familial cases of CRPS to ascertain whether the clinical features of our patients were comparable to those studies. The key findings of those studies are outlined in Table 2. The characteristics of the 'familial' patients in our case series are similar to those reported by de Rooij et al (2009). Their familial patients had an average age of onset of 33.9 years. ${ }^{16}$ The average age of onset in our case series is 33.7 years. In both studies, about $80 \%$ of the affected patients were female. The incidence of familial CRPS in the de Rooij cohort was $16 \%{ }^{16}$ while it was $6 \%$ in our smaller cohort. They reported a more frequent involvement of multiple extremities in familial patients as compared to sporadic patients. ${ }^{16}$ Although we did not have a control-group in our study for comparison, the occurrence of bilateral involvement (40\%) seems higher than the non-familial CRPS populations. Both studies employed small clinical samples, and larger populationbased studies are needed to determine the true familial incidence of familial CRPS. Nonetheless, our series lends further support to the observation that CRPS may have a familial occurrence.

A small sample size for our familial group precluded a statistical comparison between the familial and sporadic cases of CRPS. Nonetheless, it seems that patients with familial CRPS may have an early onset of symptoms. Another interesting observation in our series was a frequent history of migraine among the CRPS patients and their family members. Peterlin et al (2009) showed that patients with CRPS were 3.6 times more likely to have migraine and twice as likely to have chronic daily headaches versus the general population. ${ }^{21}$ The presence of migraine in unaffected family members of CRPS also raises the possibility that two pain conditions may be etiologically linked. It will be important to pursue these observations as they may help explicate the etiology of CRPS and migraine.

\section{Conclusions}

Identification of a familial variant of CRPS may help our understanding of the etiologic underpinnings of this disorder. Additionally, the presence of a familial variant suggests that family members of CRPS patients may be tried on preventative treatment such as vitamin $C$ and early mobilization after noxious injury or surgery to prevent the occurrence of the disease..$^{22-24}$ Further studies are needed to determine if DNA profiling or other genetic tools will help us determine the vulnerability to develop CRPS. The identification of familial CRPS may also yield genetic markers that will be helpful for diagnosis and treatment of CRPS.

\section{REFERENCES}

1. Sandroni P, Benrud-Larson LM, McClelland RL, Low PA. Complex regional pain syndrome type I: incidence and prevalence in Olmsted County, a population-based study. Pain. 2003; 103(12):199-207.

2. de Mos M, de Bruijn AG, Huygen FJ, Dieleman JP, Stricker BH, Sturkenboom MC. The incidence of complex regional pain syndrome: a population-based study. Pain. 2007; 129(1-2): $12-20$.

3. Allen G, Galer BS, Schwartz L. Epidemiology of complex regional pain syndrome: a retrospective chart review of 134 patients. Pain. 1999; 80(3):539-44.

4. Maleki J, LeBel AA, Bennett GJ, Schwartzman RJ. Patterns of spread in complex regional pain syndrome type I (reflex sympathetic dystrophy). Pain. 2000; 88(3):259-66.

5. Harden RN, Bruehl S, Galer BS, Saltz S, Bertram M, Backonja M, et al. Complex regional pain syndrome: are the IASP diagnostic criteria valid and sufficiently comprehensive? Pain. 1999; 83(2):211-9.

6. Toda K, Muneshige H, Maruishi M, Kimura H, Asou T. Headache may be a risk factor for complex regional pain syndrome. Clin Rheumatol. 2006; 25(5):728-30.

7. An HS, Hawthorne KB, Jackson WT. Reflex sympathetic dystrophy and cigarette smoking. J Hand Surg. 1988; 13(3):458-60.

8. Mailis A, Wade J. Profile of Caucasian women with possible genetic predisposition to reflex sympathetic dystrophy: a pilot study. Clin J Pain. 1994; 10(3):210-7.

9. Kemler MA, van de Vusse AC, van de Berg-Loonen EM, Barendse GA, van Kleef M,Weber WE. HLA-DQ1 associated with reflex sympathetic dystrophy. Neurology. 1999; 53(6):1350-1. 
10. van Hilton JJ, van de beek WJT, Roep BO. Multifocal or generalized tonic dystonia of complex regional pain syndrom: a distinct clinical entity associated with HLA-DR13. Ann Neurol. 2000; 48(1):113-6.

11. Albert J, Ott H. Three brothers with algodystrophy of the hip. Ann Rheum Dis. 1983; 42(4):421-4.

12. Erdmann MW, Wynn-Jones CH. 'Familial' reflex sympathetic dystrophy syndrome and amputation. Injury. 1992; 23(2):136-8.

13. Veldman PH, Reynen HM, Arntz IE, Goris RJ. Signs and symptoms of reflex sympathetic dystrophy: prospective study of 829 patients. Lancet. 1993; 342(8878):1012-6.

14. Bruscas Izu C, Beltrán Auderá CH, Jiménez Zorzo F. Polytopic and recurrent reflex sympathetic dystrophy in lower limbs in two siblings. An Med Interna. 2004; 21(4):183-4.

15. Hühne K, Leis S, Schmelz M, Rautenstrauss B, Birklein F. A polymorphic locus in the intron 16 of the human angiotensinconverting enzyme (ACE) gene is not correlated with complex regional pain syndrome I (CRPS I). Eur J Pain. 2004; 8(3): 221-5.

16. de Rooij AM, de Mos M, Sturkenboom MC, Marinus J, van den Maagdenberg AM, van Hilten JJ. Familial occurrence of complex regional pain syndrome. Eur J Pain. 2009; 13(2):171-7.

17. Higashimoto T, Baldwin EE, Gold JI, Boles RG. Reflex sympathetic dystrophy: complex regional pain syndrome type I in children with mitochondrial disease and maternal inheritance. Arch Dis Child. 2008 May; 93(5):390-7.

18. Trottier Y, Biancalana V, Mandel JL. Instability of CAG repeats in Huntington's disease: relation to parental transmission and age of onset. J Med Genet. 1994 May; 31(5):377-82.
19. Rooij AM, de Mos M, van Hilten JJ, Sturkenboom MC, Gosso MF, den Maagdenberg AM, et al. Increased risk of complex regional pain syndrome in siblings of patients? J Pain. 2009 Dec; $10(12): 1250-5$.

20. Grosen D, Chevrier C, Skytthe A, Bille C, Molsted K, Sivertsen A, et al. A cohort study of recurrence patterns among more than 54,000 relatives of oral cleft cases in Denmark: support for the multifactorial threshold model of inheritance. J Med Genet. 2009 [Epub 2009 Sep 14].

21. Peterlin BL, Rosso AL, Nair S, Young WB, Schwartzman RJ. Migraine may be a risk factor for the development of complex regional pain syndrome. Cephalalgia. 2009 Jul 9 [Epub 2009 Jul 9].

22. Oerlemans HM, Oostendrop RA, de Boo T, Goris RJ. Pain and reduced mobility in complex regional pain syndrome I: outcome of a prospective randomized controlled clinical trial of adjuvant physical therapy versus occupational therapy. Pain. 1999; 83(1): 77-83.

23. Zollinger PE, Tuinebreijer WE, Kreis RW, Breederveld RS. Effect of vitamin $\mathrm{C}$ on frequency of reflex sympathetic dystrophy in wrist fractures: a randomised trial. Lancet. 1999; 354(9195): 2025-8.

24. Petchkrua W, Weiss DJ, Patel RR. Reassessment of the incidence of complex regional pain syndrome type 1 following stroke. Neurorehabil Neural Repair. 2000; 14(1):59-63. 